\title{
Quantification Detection of Probiotic Bacteria Based on Plasmonic Gold-Nanoparticle Sensors
}

\author{
Fangqi Di \\ Victoria Junior College, Singapore \\ Email: fangqidi0727@gmail.com
}

How to cite this paper: Di, F.Q. (2020) Quantification Detection of Probiotic Bacteria Based on Plasmonic Gold-Nanoparticle Sensors. American Journal of Analytical Chemistry, 11, 213-220.

https://doi.org/10.4236/ajac.2020.115017

Received: March 24, 2020

Accepted: May 18, 2020

Published: May 21, 2020

Copyright $\odot 2020$ by author(s) and Scientific Research Publishing Inc. This work is licensed under the Creative Commons Attribution-NonCommercial International License (CC BY-NC 4.0). http://creativecommons.org/licenses/by-nc/4.0/ (c) (i) (5) Open Access

\begin{abstract}
Probiotic products are of significant research interest in recent years due to their powerful health benefits. One of the most popular commercial probiotic products is probiotic milk drinks containing Lactobacillus bacteria. The quality and effectiveness of such drinks are highly dependent on their bacterial content. However, such information is only available in producers' advertisements-which may be misleading, and there are few studies done on the true bacterial content of these drinks. More significantly, conventional methods of measuring Lactobacillus bacterial content are laborious and time-consuming. Hence, this research aims to develop a fast and easy test that shows visible results rapidly and can be applied to other Lactobacillus-containing products. Recent developments have presented gold nanoparticles as a strong candidate for various applications in chemistry, physics, and biology for their unique optical properties. One essential optical property of gold nanoparticles is their red or blue color due to plasmon resonance. In this research, strong potential for this property of gold nanoparticles is recognised in a novel method of measuring the bacterial CFU in probiotic milk drinks. Gold nanoparticles function as the key material and indicator in this method as they are found capable of adhering to the Lactobacillus bacteria. The bacterial CFU can then be determined from the amount of gold nanoparticles attached to the bacteria. The eventual measuring scheme established enables fast (15 - 16 times faster than colony counting) and convenient (a sterile environment is not necessary) tests of the bacterial CFU in different probiotic milk drinks and has great potential in other related applications.
\end{abstract}

\section{Keywords}

Probiotics, Gold Nanoparticles, Plasmonic, Bacteria Sensors

\section{Introduction}

In recent years, probiotics products have been rising in popularity for their nu- 
merous health benefits, attracting significant research interest worldwide. One of the most popular types of probiotic products is sweetened milk drink containing Lactobacillus bacteria, as some Lactobacillus strains exhibit powerful health benefits including reducing risks of infectious, inflammatory and allergic diseases [1], alleviating the symptoms of lactose intolerance [2], and improving oral health [3]. Due to these attractive properties, commercially available probiotic milk drinks are often advertised as healthy and rich in good bacteria. For instance, Yakult, a Japanese probiotic milk drinks brand, claims that there are 10 billion Lactobacillus casei strain Shirota bacteria in $100 \mathrm{~mL}$ of the drink (https://yakult.com.sg/). Therefore, the concentration and survival rate of Lactobacillus bacteria are important indicators of the quality and effectiveness of these drinks. To quantify the number of bacteria in probiotic milk drinks, researchers conventionally use methods such as colony counting-which is time-consuming and laborious as it can take up to 3 days for visible results to appear. Thus, to easily estimate bacterial colony forming units (CFU) and make comparisons across samples, a test that shows visible results rapidly would be more desirable.

Gold nanoparticles (Au NPs) are widely used in biological applications such as labeling, delivering, heating, and sensing for their unique optical and thermal properties [4]. For example, Au NPs can be used for sensitive and highly specific immunoassays to detect the presence of certain antibodies, and this technology is proven helpful for early diagnosis of diseases such as cancer [5]. Additionally, $\mathrm{Au}$ NPs are red or blue due to specific plasmon resonance [6], and different concentrations of Au NPs can be directly compared through the intensity of their colors. Au NPs are used in this method because they are found capable of adhering to the Lactobacillus bacteria and causing aggregation of the bacteria. The binding of gold nanoparticles and bacteria can be further utilized to determine the bacterial CFU, as the amount of Au NPs attached to the bacteria is directly related to the number of bacteria present. Thus, by magnifying and comparing the color intensity of the resultant mixture, a fast and easy estimation of the bacterial CFU in different probiotic milk drinks can be achieved.

In this report, a novel method of measuring the bacterial CFU in probiotic milk drinks is proposed, which utilizes gold nanoparticles as the key material and indicator. Au NPs can be used as bacteria biosensors while capped with suitable materials, which are able to bind to bacteria through electrostatic interactions. For instance, cysteine-modified Au NPs can detect E. coli 0157: H7; aptamer-functionalized Au NPs are capable of recognizing S. typhimurium; antibody-functionalized Au NPs can be used to detect Lactobacillus spp. and Staphylococcus aureus; and polyethylenimine (PEI)-capped Au NPs are also a biosensor for the rapid detection of bacteria [7]. However, no previous research focuses on using Au NPs alone to detect bacteria, and there is limited discussion on the interactions between Au NPs and probiotic bacteria. Hence, this paper looks at Au NPs-based detection of bacteria from a new angle. 
The main aim of this research is to achieve rapid estimation and comparison of the bacterial CFU in probiotic milk drinks through visible and straightforward results, so as to make a basic judgement of the quality and effectiveness of different probiotic milk drinks. Besides, the research aims to evaluate the impact of storage conditions on the quality of probiotic milk drinks.

\section{Methods and Materials}

\subsection{Synthesis of Au NPs}

$20 \mathrm{~mL}$ of $1 \mathrm{mmol} / \mathrm{L} \mathrm{HAuCl}_{4}$ is boiled, after which $2 \mathrm{~mL}$ of $1 \%$ trisodium citrate dihydrate is immediately added. The final mixture is left to stand for 10 minutes. The Au NP solution and its absorption spectrum are obtained from Figure 1.

\subsection{Purification of Lactobacillus Bacteria from Probiotic Milk Drinks}

$1 \mathrm{~mL}$ of MRS broth is mixed with $1 \mathrm{~mL}$ of Yakult probiotic milk drink in a 15 $\mathrm{mL}$ centrifuge tube. The mixture is then incubated at $37^{\circ} \mathrm{C}$ for 1 hour. The MRS present will separate the mixture into two layers by precipitating most skimmed milk solids (see from Figure 2). The supernatant fraction contains mostly bacteria and MRS broth and is centrifuged at $100 \mathrm{rcf}$ for 3 minutes to remove the leftover milk solids, after which the supernatant fraction is extracted for another

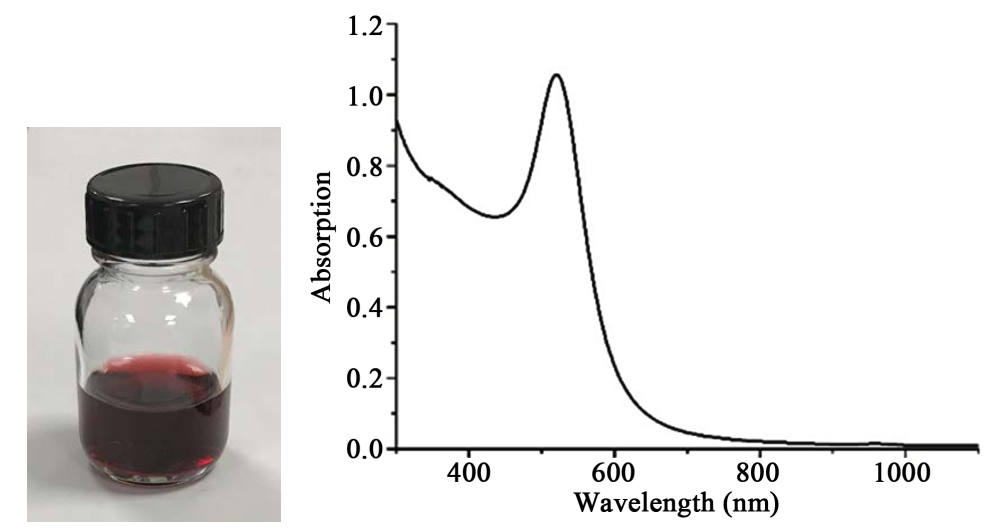

Figure 1. Au NP solution synthesized and its absorption spectrum.

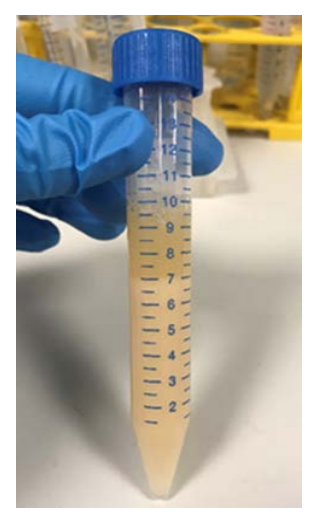

Figure 2. Yakult-MRS broth mixture separated into layers after incubation. 
round of centrifugation at $1500 \mathrm{rcf}$ for 5 minutes. At this step, the bacteria in the mixture would have been precipitated. The precipitate is then washed twice with deionized water to remove excess MRS. The entire purification process is repeated for Vitagen and Yoyi $\mathrm{C}$ probiotic drinks. The resulting solid in each sample is thoroughly dissolved in $1 \mathrm{~mL}$ of deionized water.

\subsection{Binding Au NPs with Lactobacillus Bacteria}

Take a $1 \mathrm{~mL}$ sample of Yakult bacteria from last step, add $100 \mu \mathrm{L}$ of Au NPs solution from the first step and mix thoroughly. Let the mixture stand for $10 \mathrm{mi}$ nutes before putting it in the centrifuge at $1500 \mathrm{rcf}$ for 5 minutes. The supernatant fraction containing excess Au NPs is then removed from the mixture. The resulting solid is washed in the centrifuge at $1500 \mathrm{rcf}$ for 5 minutes once with deionized water to remove remaining traces of free Au NPs. The above method is repeated for purified skimmed milk solids as the control group (see from Figure 3).

\subsection{Preparation and Testing of the Growth Solution for Au NPs}

To amplify the color intensity of the Au NP-bacteria mixture, a growth solution for $\mathrm{Au}$ NPs is prepared by mixing $400 \mu \mathrm{L}$ of $0.1 \mathrm{~mol} / \mathrm{L} \mathrm{CTAB}, 540 \mu \mathrm{L}$ of 5.0 $\mathrm{mmol} / \mathrm{L} \mathrm{HAuCl}_{4}$ and $60 \mu \mathrm{L}$ of $0.1 \mathrm{~mol} / \mathrm{L}$ ascorbic acid (AA). The resulting growth solution is a colorless solution that does not change color if left to stand on its own, which indicates that the solution is stable enough to inhibit the growth of Au NPs in itself. As $100 \mu \mathrm{L}$ of Au NP solution prepared in step one is added to $1 \mathrm{~mL}$ of the growth solution, the mixture turns an intense red color immediately. The resulting mixture is compared side by side with a mixture of $100 \mu \mathrm{L}$ of $\mathrm{Au} \mathrm{NP}$ solution and $1 \mathrm{~mL}$ of deionized water, and the mixture with the growth solution shows a much darker red color (see from Figure 4).
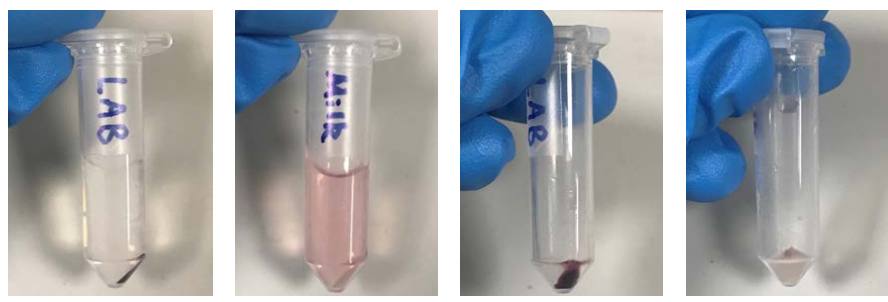

Figure 3. Au NP-bacteria mixture and Au NP-milk solids mixture after centrifugation (left: with supernatant fluid; right: without supernatant fluid).
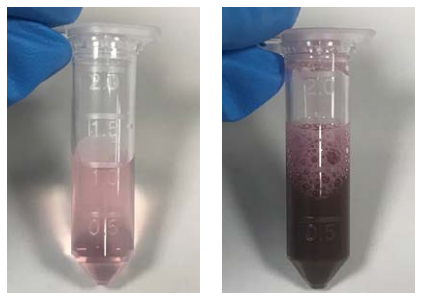

Figure 4. Left: mixture of $100 \mu \mathrm{L}$ Au NP solution and $1 \mathrm{~mL} \mathrm{H}_{2} \mathrm{O}$; right: mixture of $100 \mu \mathrm{L} \mathrm{Au} \mathrm{NP}$ solution and $1 \mathrm{~mL}$ growth solution. 


\subsection{Comparing Results from Different Bacterial CFU and Different Brands}

Bacteria solutions of Yakult, Vitagen and Yoyi C from step two are prepared with different concentrations (original concentration, 10 times dilution, and 100 times dilution). Three sets of bacteria solutions of Yakult are prepared to investigate the repeatability of the method. Bind Au NPs with the bacteria in each sample using the method in step three. Add $100 \mu \mathrm{L}$ of deionized water to each sample to thoroughly dissolve the resulting solid. Drop $1 \mu \mathrm{L}$ of each sample onto a piece of filter paper as shown in Figure 5. After the droplets are dried, drop growth solution onto the filter paper to immerse the paper entirely. Wait 1 - 2 minutes for the color of the droplets to be significantly intensified.

\subsection{Colony Counting to Match Color Intensity with Bacterial CFU}

Gradient dilution of each probiotic milk drink is carried out (10 - 10 $0^{7}$ times dilution). $5 \mathrm{~mL}$ of each concentration is dropped onto the surface of $10 \mathrm{~mL}$ MRS agar in a petri dish. The agar plates are then incubated at $37^{\circ} \mathrm{C}$ for two overnights under the condition of $5 \% \mathrm{CO}_{2}$. The bacterial $\mathrm{CFU}$ of the initial probiotic milk drinks is then calculated from the number of bacterial colonies formed.

\subsection{Comparing Results from Different Storage Conditions}

Yakult probiotic milk drink is treated under two conditions deemed unfavorable for the survival of Lactobacillus bacteria. One $50 \mathrm{~mL}$ sample of uncontaminated Yakult is left at room temperature $\left(22^{\circ} \mathrm{C}\right)$ for 5 days. Another identical sample is heated at $70^{\circ} \mathrm{C}$ for 15 minutes. The samples are purified and tested on a filter paper according to step two, three and five (see from Figure 6).
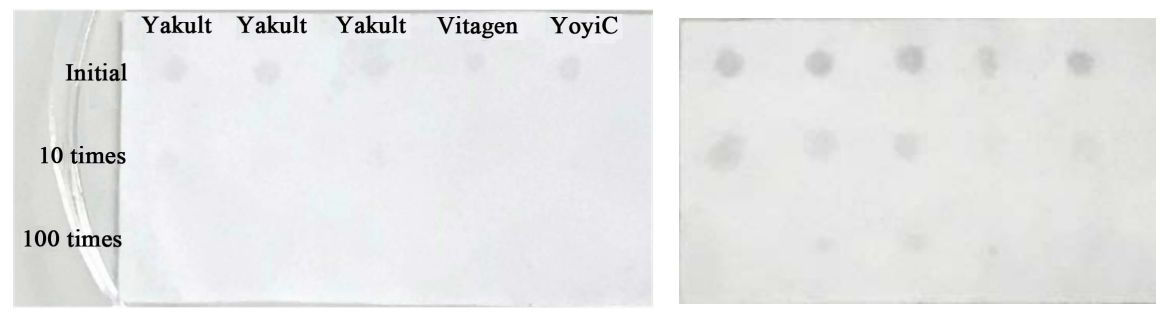

Figure 5. Au NP-bacteria mixtures from different brands of probiotic milk drinks (left: before addition of growth solution; right: after addition of growth solution).

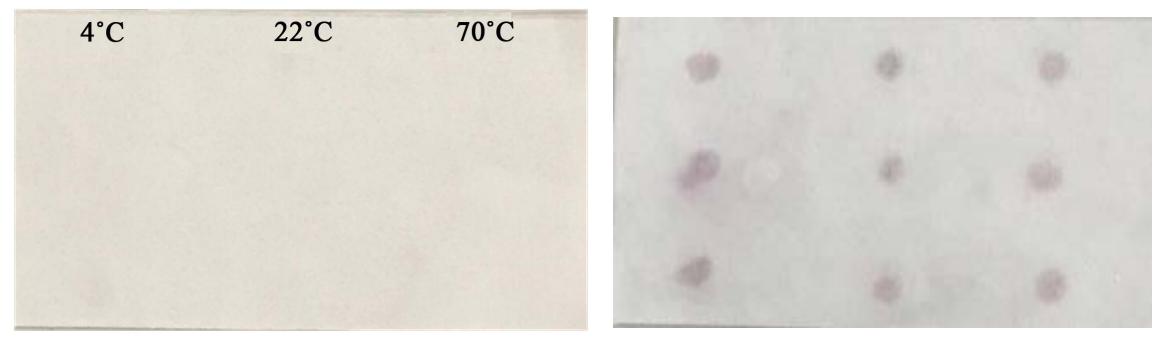

Figure 6. Au NP-bacteria mixtures under different storage conditions (left: before addition of growth solution; right: after addition of growth solution). 


\section{Results and Discussion}

$\mathrm{Au}$ NPs are able to adhere to the surface of the Lactobacillus bacteria in Yakult and cause the bacteria to aggregate (Figure 7). However, Au NPs do not adhere to skimmed milk solids in probiotic milk drinks, as the milk solids do not turn red after centrifugation (a sign of presence of red Au NPs). This means Au NPs only bind with bacteria, thus the amount of Au NPs bound to bacteria depends on the number of bacteria present.

After the addition of the growth solution for Au NPs, the color intensities of $\mathrm{Au}$ NP-bacteria mixtures of two consecutive bacterial CFU differ greatly (e.g. the initial concentration shows a much darker purple than that of 10 times dilution) (Figure 5). This indicates that there is a positive relationship between the color intensity of Au NP-bacteria mixture and the bacterial CFU. According to results of colony counting, the color intensity of the initial bacteria concentration corresponds to $10^{8} \mathrm{CFU}$ per $\mathrm{mL}$ for all three brands of probiotic milk drinks, indicating that these drinks indeed contain the number of Lactobacillus bacteria as advertised.

With the aid of the growth solution, the Au NP-bacteria mixtures from bacteria under all three storage conditions show equally intense red color with minimal difference (Figure 6). This result is confirmed by the colony counting method and reveals important information about probiotic milk drinks and the bacteria in them: the Lactobacillus bacteria in probiotic milk drinks have strong vitality, thus they are most likely live bacteria when the drinks are first purchased. This implies that the method in this report gives a rather accurate estimate of the number of live bacteria in probiotic milk drinks, and hence is useful for assessing the quality and effectiveness of these drinks.

The growth solution for Au NPs is able to significantly amplify the color of Au NPs (Figure 4). Thus, the color intensity of the Au NP-bacteria mixtures is greatly enhanced by the growth solution, and differences in color intensity are magnified if there are any (Figure 5 and Figure 6). Therefore, the growth solution prepared effectively aids the indicating function of Au NPs and is essential for this method.
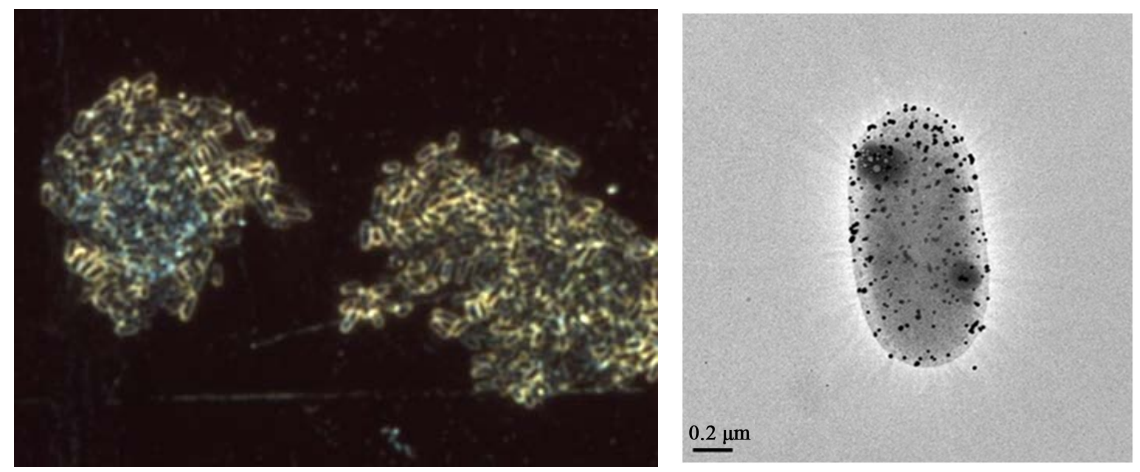

Figure 7. Left: microscope image of aggregated Au NP-bacteria mixture; right: TEM image of a single bacteria with Au NP attached to its surface. 
However, this method also has its limitations. One major limitation is that it cannot be applied to all types of probiotic milk drinks. For instance, Meiji probiotic milk drink contains bacteria that do not interact with Au NPs (which we suspect to be Streptococcus thermophilus), making this method unsuitable for estimating the bacterial CFU in the drink. Hence, improvements can be made to the procedures or materials used in this method for it to be feasible for a wider range of probiotic milk drinks and even other products containing Lactobacillus bacteria.

\section{Conclusions and Recommendations for Future Work}

Evidently, for Yakult, Vitagen and Yoyi C probiotic milk drinks and other similar products, the above method can yield a fast and visible estimation of the bacterial CFU of Lactobacillus bacteria in them, allowing a basic assessment of the quality and effectiveness of such products. Gold nanoparticles' unique optical property and ability to adhere to Lactobacillus bacteria enable them to be the crucial indicator of the bacteria number, laying the foundation for this method.

In the future, studies can be done on the feasibility of this method for other probiotic products containing Lactobacillus bacteria and simplification of its procedures, so as to further explore the application potential of the method. For example, the size and shape of gold nanoparticles and the composition of growth solution should be key considerations for optimal efficacy of this method, and the mechanism behind binding of gold nanoparticles and bacteria should be another important exploration. Additionally, important benchmarks such as the detection limit, linear range and selectivity of the test also require further specification.

\section{Acknowledgements}

I would like to express my sincere gratitude for Professor Duan Hongwei for introducing me to this area of study and allowing me to conduct my experiments in School of Chemical and Biomedical Engineering in Nanyang Technological University. I would also like to thank Dr Hou Shuai for his invaluable time, guidance, advice and support in supervising this project. Lastly, I would like to thank the Nanyang Research Program and Nanyang Technological University for endorsing this project.

\section{Conflicts of Interest}

The author declares no conflicts of interest regarding the publication of this paper.

\section{References}

[1] Isolauri, E., Salminen, S. and Ouwehand, A.C. (2004) Probiotics. Best Practice \& Research Clinical Gastroenterology, 18, 299-313.

https://doi.org/10.1016/j.bpg.2003.10.006 
[2] Goldin, B.R. (1998) Health Benefits of Probiotics. British Journal of Nutrition, 80, S203-S207. https://doi.org/10.1017/S0007114500006036

[3] Haukioja, A. (2010) Probiotics and Oral Health. European Journal of Dentistry, 4, 348-355. https://doi.org/10.1055/s-0039-1697851

[4] Sperling, R.A., Gil, P.R., Zhang, F., Zanellaa, M. and Parak, W.J. (2008) Biological Applications of Gold Nanoparticles. Chemical Society Reviews, 37, 1896-1908. https://doi.org/10.1039/b712170a

[5] Slagle, K.M. and Ghosn, S.J. (1996) Immunoassays Tools for Sensitive, Specific, and Accurate Test Results. Laboratory Medicine, 27, 177-183. https://doi.org/10.1093/labmed/27.3.177

[6] Eustis, S. and el-Sayed, M.A. (2006) Why Gold Nanoparticles Are More Precious than Pretty Gold: Noble Metal Surface Plasmon Resonance and Its Enhancement of the Radiative and Nonradiative Properties of Nanocrystals of Different Shapes. Chemical Society Reviews, 35, 209-217. https://doi.org/10.1039/B514191E

[7] Mocan, T., Matea, C.T., Pop, T., Mosteanu, O., Buzoianu, A.D., Puia, C., Iancu, C. and Mocan, L. (2017) Development of Nanoparticle-Based Optical Sensors for Pathogenic Bacterial Detection. Journal of Nanobiotechnology, 15, Article No. 25. https://doi.org/10.1186/s12951-017-0260-y 